\title{
De novo design of potent and resilient hACE2 decoys to neutralize SARS-CoV-2
}

\author{
Thomas W. Linsky*, Renan Vergara ${ }^{1 *}$, Nuria Codina ${ }^{1 *}$, Jorgen W. Nelson ${ }^{1 *}$, Matthew J. Walker', Wen Su², \\ Christopher O. Barnes ${ }^{3}$, Tien-Ying Hsiang ${ }^{4}$, Katharina Esser-Nobis ${ }^{4}$, Kevin Yu' ${ }^{1}$ Z. Beau Reneer ${ }^{5}$, \\ Yixuan J. Hou ${ }^{4}$, Tanu Priya', Masaya Mitsumoto', Avery Pong', Uland Y. Lau', Marsha L. Mason', Jerry Chen', \\ Alex Chen', Tania Berrocal', Hong Peng', Nicole S. Clairmont', Javier Castellanos', Yu-Ru Lin', \\ Anna Josephson-Day', Ralph S. Baric ${ }^{6}$, Deborah H. Fuller ${ }^{7}$, Carl D. Walkey' ${ }^{1}$ Ted M. Ross ${ }^{5,8}$, Ryan Swanson', \\ Pamela J. Bjorkman ${ }^{3}$, Michael Gale Jr. ${ }^{4}$, Luis M. Blancas-Mejia', Hui-Ling Yen², Daniel-Adriano Silva' ${ }^{1}$
}

${ }^{1}$ Neoleukin Therapeutics Inc., Seattle, WA, USA. ${ }^{2}$ School of Public Health, Li Ka Shing Faculty of Medicine, University of Hong Kong, Hong Kong Special Administrative Region, China. ${ }^{3}$ Division of Biology and Biological Engineering, California Institute of Technology, Pasadena, CA, USA. ${ }^{4}$ Center for Innate Immunity and Immune Disease, Department of Immunology, University of Washington, Seattle, WA, USA. ${ }^{5}$ Center for Vaccines and Immunology, University of Georgia, Athens, GA, USA. ${ }^{6}$ Department of Epidemiology, University of North Carolina at Chapel Hill, Chapel Hill, NC, USA. ${ }^{7}$ Department of Microbiology, University of Washington, Seattle, WA, USA. ${ }^{8}$ Department of Infectious Diseases, University of Georgia, Athens, GA, USA.

*These authors contributed equally to this work.

†Corresponding author. Email: dadriano@neoleukin.com

We developed a de novo protein design strategy to swiftly engineer decoys for neutralizing pathogens that exploit extracellular host proteins to infect the cell. Our pipeline allowed the design, validation, and optimization of de novo hACE2 decoys to neutralize SARS-CoV-2. The best decoy, CTC-445.2, binds with low nanomolar affinity and high specificity to the RBD of the spike protein. Cryo-EM shows that the design is accurate and can simultaneously bind to all three RBDs of a single spike protein. Because the decoy replicates the spike protein target interface in hACE2, it is intrinsically resilient to viral mutational escape. A bivalent decoy, CTC-445.2d, shows $~ 10$-fold improvement in binding. CTC-445.2d potently neutralizes SARS-CoV-2 infection of cells in vitro and a single intranasal prophylactic dose of decoy protected Syrian hamsters from a subsequent lethal SARS-CoV-2 challenge.

Since its emergence as a global pandemic in December of 2019, SARS-CoV-2 has caused millions of Coronavirus Disease 2019 (COVID-19) cases. The need for effective strategies to prevent and treat the disease remains urgent (1). There are multiple ongoing efforts to develop prophylactics and therapeutics using various approaches (2) such as vaccination (3), traditional protein engineering $(1,4,5)$, de novo protein design (6) and small molecule drug discovery (7). A challenge is that the high mutational rate of positive sense single-strand RNA (+ssRNA) viruses (8-10) can often lead to viral escape (11), which could compromise the efficacy of many SARS$\mathrm{CoV}-2$ therapeutics under development. Several mutations have already occurred in the S protein of SARS-CoV-2 in the infected population (12), (13). Deep sequencing studies of the receptor binding domain (RBD) have shown that simple mutations can enable the virus to escape known neutralizing antibodies or to increase its binding affinity for human angiotensin converting enzyme 2 (hACE2) $(14,15)$, the membrane protein that the virus exploits to gain entry into the cell. A pressing need therefore exists to develop novel therapeutics that can be more resistant to SARS-CoV-2 mutational escape.

Traditional approaches to combat viruses (e.g., vaccination and monoclonal antibodies) rely on molecules interacting with the pathogens in a way that is fundamentally different than how the pathogen engages with its cellular targets $(16,17)$. Viruses can be selected to evade neutralization, undergoing protein mutations that prevent recognition by the neutralizing molecules (e.g., antibodies) while preserving viral fitness. To address these challenges, we have developed a computational protein design strategy that enables the rapid and accurate design of hyperstable de novo protein "decoys" that replicate the protein receptor interface that a virus binds to in order to infect a cell. The decoys can achieve a similar or even higher affinity than the original protein receptor by stabilizing the binding interface. Therefore, at an optimal concentration, the decoys can outcompete viral interaction with the cell.

SARS-CoV-2 invades host cells in a two-step process (1820 ). The S protein RBD attaches to the cell by binding to hACE2, a membrane associated protein, triggering protease mediated fusion with the cell membrane (21). The process is similar to the beta-coronaviruses HCoV-NL63 and SARS-CoV1, which also target hACE2 for cellular entry (22). In principle, inhibiting the viral interaction with hACE2 should prevent infection. We applied our design strategy to engineer, validate and optimize de novo hACE2 decoys to neutralize SARS- 
CoV-2 infection (Fig. 1J and fig. S1). The design of the decoys started by identifying the structural motifs that form the hACE2 binding interface with the SARS-CoV-2 RBD. We based our effort on three publicly available structures of hACE2 in complex with the RDB of the S protein for SARSCoV-1 (PDB: 6CS2) and SARS-CoV-2 (PDBs: 6VW1, 6M17) (23$25)$. Four discontiguous binding elements were identified (Fig. 1A), the three largest interacting motifs were selected to build the de novo decoys, two long alpha helices ( $\mathrm{H} 1$ and $\mathrm{H} 2)$ and a short beta hairpin (EE3) (Fig. 1A and fig. S2). To generate molecules that are biologically inert for humans, our computational design strategy avoided incorporating elements of hACE2 that are known (or predicted) to be biologically active, such as the catalytic site. Inspired by recent developments in the design of de novo structural elements (26-29), we built new disembodied de novo secondary structure elements tailored to support the target structural elements in a way that is both compatible with globular folding and stabilize the binding interface (Fig. 1B and materials and methods). Then, in a strategy similar to the design of Neoleukin-2/15 (Neo$2 / 15)(26,30)$, a combinatorial design approach based on Rosetta's "protein_mimic_designer" was used to generate multiple fully-connected protein topologies containing all the desired structural and binding elements (26). The design of the protein decoys was constrained to fully preserve-intact up to each amino acid's conformation-the target binding interface (Fig. 1, A and B, and fig. S2), so that the de novo proteins can be resilient to viral mutational escape. Rosetta (31) was then used to generate amino acid sequences predicted to fold into the target structures, and evaluated the designs with an automatic filtering pipeline based on nine computational parameters, including predictions of smooth folding funnels into a stable native state (Fig. 1, C and D) (32).

Approximately 35,000 computational ACE2 decoys were generated, and the top ranking 196 designs (see the materials and methods) were selected for experimental testing for binding to SARS-CoV-2 RBD using yeast display (Fig. 1E). With no further optimization, the design CTC-445 showed stong/nanomolar and specific binding for SARS-CoV-2 RBD (Fig. 1E, fig. S3, and materials and methods). CTC-445 is a 160 amino acid protein comprising 18 of the natural amino acids (it does not contain cysteine or tryptophan residues). It exhibits $\sim 10-$ fold weaker binding affinity for SARS-CoV-2 than hACE2 $\left(K_{\mathrm{D}}\right.$ $=357 \mathrm{nM}, K_{\mathrm{D}}=31 \mathrm{nM}$, respectively; table S1), and as a result, CTC-445 was a weak competitor of SARS-CoV-2 RBD binding to hACE2 $\left(\mathrm{IC}_{50} @\right.$ hACE2[0.4nM] $=1.7 \mu \mathrm{M}$; Fig. 1I). We determined that low potency of CTC-445 is due to a certain degree of instability of its folded state $\left(\Delta \mathrm{G}_{\mathrm{NI}} \sim-2.7 \mathrm{kcal} \mathrm{mol}^{-1}, \mathrm{~T}_{\mathrm{m}} \sim 75.3^{\circ} \mathrm{C}\right.$; Figs. $1 \mathrm{~F}$ and $2 \mathrm{~B}$ and fig. S5). A single round of directed evolution to improve stability and binding affinity, and subsequently the rational combination of the five most frequent observed mutations (none of them in the binding interface) led to the protein decoy CTC-445.2 (Fig. 1G, figs. S6 and S7, table S2, and materials and methods). CTC- 445.2 is predominantly monomeric (Fig. $1 \mathrm{H}$ and fig. S8), thermodynamically hyperstable $\left(\triangle \mathrm{G}_{\mathrm{NI}} \sim-5.0 \mathrm{kcal} \mathrm{mol}^{-1}, \mathrm{~T}_{\mathrm{m}} \sim 93^{\circ} \mathrm{C}\right.$; Fig. $2 \mathrm{~B}$ and fig. S5), exhibits low nanomolar affinity for the RBD of SARSCoV-2 $\left(K_{\mathrm{D}} \sim 21.0 \mathrm{nM}\right.$; table S1), has improved cross-reactivity to SARS-CoV-1 $\left(K_{D} \sim 7.1 \mu \mathrm{M}\right.$; Fig. $2 \mathrm{C}$ and table $\left.\mathrm{S} 1\right)$, and can efficiently compete hACE2 binding to the SARS-CoV-2 RBD ( $\mathrm{IC}_{50} @$ hACE2[0.4nM] $~ 10.4 \mathrm{nM}$; Fig. 1I). The amino acid sequence of CTC-445.2 has little identity with hACE2, in terms of either linear or structurally aligned sequence (ClustalW 22\%, MICAN 34\%, respectively; fig. S9). Serial-duplication (i.e., increase in avidity) of CTC-445.2 led to higher potency molecules with favorable biochemical properties. For example, CTC-445.2d (Fig. 2A), a bivalent version of CTC-445.2, has a $\sim 10$-fold improvement in binding affinity for both SARS-CoV$2 \mathrm{RBD}\left(K_{D} \sim 3.5 \mathrm{nM}\right.$; table S1) and SARS-CoV-1 RBD $\left(K_{D} \sim 587\right.$ nM; Fig. $2 \mathrm{C}$ and table S1), and a similar increase in its ability to compete with hACE2 binding to SARS-CoV-2 RBD (IC 50 @ hACE2[0.4nM] $\sim 700$ pM; Fig. 1I). A trivalent version of CTC-445.2 resulted in even higher (picomolar) binding affinity and a matching hACE2 competition potency $\left(K_{\mathrm{D}} \sim 270 \mathrm{pM}, \mathrm{IC}_{50} @\right.$ hACE2[0.4nM] $\sim 110$ pM; fig. S10 and table S1). In a cross-reactivity binding assay containing $>21,000$ human proteins, we confirmed that CTC-445.2d binds to the SARS-CoV-2 RBD with high selectivity (fig. S11 and materials and methods).

Single-particle cryo-EM structures of CTC-445.2 in complex with the SARS-CoV-2 S trimer shows that the de novo decoy is capable of simultaneous binding to all 3 RBDs of the SARS-CoV-2 trimeric S protein, both in "up" and "partiallydown" RBD conformations (Fig. 3, A to D, and fig. S12). To accurately model the CTC-445.2-RBD interactions, we used focused classification and local refinement on the subset of particles that showed CTC-445.2 bound to a "partially-down" $\mathrm{RBD}$, which yielded a $4.1 \AA \AA$ map with improved CTC-RBD features relative to CTC-RBD regions on "up" RBDs (Fig. 3, A to $\mathrm{D}$, and figs. S12 and S13). The computationally derived model of CTC-445.2 closely matches the cryo-EM determined structure $(\mathrm{C} \propto \mathrm{RMSD}=1.1 \AA)$, with minor differences observed in the $\mathrm{N}$-terminal EE3 and H2 helix (Fig. 3, E to H). As designed, the binding interface of the SARS-CoV-2 RBD with CTC-445.2 closely mirrors the target hACE2 interface. We used site saturation mutagenesis (SSM; see the materials and methods) $(33,34)$ to explore the effect of single amino acid substitutions in CTC-445.2 on its binding to the SARS-CoV-2 RBD (Fig. 3, I and J). The experiment shows that mutations in the core of the design are disallowed, and mutations in surface/exposed residues are generally tolerated (Fig. 3, I and J). The SSM experiment also reveals that there is room to further improve the affinity of the protein by introducing mutations in the binding interface (Fig. 3I), although doing so would break the hACE2 structural mirroring of the de novo decoy. 
We also performed a SSM experiment for the SARS-CoV2 RBD binding interface, to compare the effect of single amino acid substitution on the binding to hACE2 or CTC445.2. As predicted, the effects of $\sim 1700$ SARS-CoV-2 RBD mutations showed a strong correlation between binding to hACE2 and CTC-445.2 ( $\mathrm{R}^{2}=0.84$, Pearson's $\mathrm{r}=0.92$; Fig. 4 and fig. S14), highlighting the decoy's intrinsic resiliency to mutational escape. Notably, at low target concentrations (100 pM), CTC-445.2 has a large binding advantage over ACE2 for many of the RBD mutations (fig. S14), likely a result of both its higher stability and smaller size. Although CTC-445.2 is resilient to viral mutations in the RBD binding interface, we observed some decoy binding-weakening mutations that have a lesser effect on hACE2 binding. Therefore, viral mutational escape might still be possible if multiple (decoy bindingweakening) RBD mutations are combined.

The high and specific binding affinity of the optimized de novo protein decoys translated into effective and specific in vitro neutralization of SARS-CoV-2 viral infection (Fig. 5). In vitro, the presence of the de novo decoys has no impact on mammalian cell viability (Fig. 5A and fig. S15) or the enzymatic activity of hACE2 (fig. S16). Both of the decoys were able to fully neutralize viral infection in in vitro systems of cell infection. Briefly, in a Vesicular stomatitis virus (VSV) pseudovirus system expressing the SARS-CoV-2 S protein, the decoys specifically protected HEK 293T cells overexpressing hACE2 from infection (fig. S15). The decoys also were able to fully neutralize infection by SARS-CoV-2 (SARS-CoV-2 nanoLuc; see the materials and methods) in the lung epithelial cell line Calu-3 expressing both ACE2 and the transmembrane protease serine 2 (TMPRSS2) $(35,36)\left(\mathrm{EC}_{50}<5 \mathrm{nM}\right.$ at $\mathrm{MOI}=1.0$; Fig. $5 \mathrm{~A}$ ). In an in vitro time-of-addition assay using the Vero E6 cell line, CTC-445.2 and CTC-445.2d were most effective at neutralizing SARS-CoV-2 infection when continuously present in the cell media throughout the full course of infection (as opposed to only before or after infection; Fig. 5A and figs. S16 to S18), confirming that their mechanism of viral inhibition is extracellular neutralization of the virus.

To determine the potential of our molecules to be used as respiratory delivered therapeutics, we intranasally (i.n.) administered a single dose of CTC-445.2d to Balb/c mice (100 $\mu \mathrm{g}$ dose of CTC-445.2d in a $30 \mu \mathrm{L}$ droplet), and observed presence of the fully functional decoy for more than 24 hours in the lungs and respiratory tract of mice (Fig. 5B and fig. S19). A 14-day course of daily CTC-445.2d i.n. administration in mice (100 $\mu \mathrm{g}$ of CTC-445.2d in a $30 \mu \mathrm{L}$ droplet) was well tolerated, causing no adverse effects (Fig. 5B). In a Syrian hamster model for SARS-CoV-2 infection, a single prophylactic i.n. dose of CTC-445.2d (560 $\mu \mathrm{g}$ of CTC-445.2d in a $100 \mu \mathrm{L}$ droplet) administered 12 hours before the viral challenge afforded $100 \%$ survival from a lethal SARS-CoV-2 challenge $\left(5 \times 10^{5}\right.$ plaque forming units of SARS-CoV-2; Fig. 5C).
Specifically, by day 7 , all control animals $(n=7)$ that received the viral challenge but not CTC-445.2d exhibited significant respiratory distress and required euthanasia. In contrast, hamsters that received a single dose of CTC-445.2d 12 hours prior to challenge all survived $(n=8)$ with modest weight loss and little or no clinical signs of respiratory distress (Fig. 5C and table S5).

Our de novo protein design approach to generate decoys is orthogonal to traditional therapeutics and has the potential to better overcome mutational viral evasion. Natural proteins repurposed often present significant challenges for development as therapeutics, such as low stability that can complicate manufacturing, transport and storage; residual (and undesirable) biological activity; and the risk of eliciting an autoimmune response (37-46). In contrast, the de novo protein decoys are amenable for large scale manufacturing in traditional bacterial systems, and their thermodynamic hyperstability can enable simplified transport and storage. Other recent protein engineering efforts have generated neutralizing proteins characterized by extreme high binding affinities for SARS-CoV-2, with $K_{D}$ 's ranging from low nanomolar to femtomolar (e.g., mAb 2B04 EC50 (47); LCB1, EC50 (6); and the nanobody $\mathrm{Nb} 6$ (48)). Nevertheless, the de novo decoy's resilience to viral escape is a distinctive feature of our design strategy (Fig. 4 and figs. S14 and S20). A possible shortcoming is that a decoy's requirement to replicate a natural binding interface can intrinsically limit the maximum binding affinity attainable. However, we have demonstrated that the binding affinity (and potency) of the de novo decoys can be increased both by further sequence optimization (e.g., CTC-445.3d; fig. S21) or through avidity, allowing our trivalent decoy CTC-445.2t to reach the picomolar affinity range (Fig. 3I and fig. S10). It is possible that avid versions of CTC-445.2 coupled with more refined linkers (rigid and with proper spacing for binding simultaneously to multiple RBD subunits) might lead to larger increases in binding potency.

We demonstrate rapid design of a therapeutic lead; further speed improvements to our pipeline are theoretically attainable, for example by using high throughput experiments to rapidly select and optimize the designs (Fig. 1G).

\section{REFERENCES AND NOTES}

1. D. E. Gordon, G. M. Jang, M. Bouhaddou, J. Xu, K. Obernier, K. M. White, M. J. O'Meara, V. V. Rezelj, J. Z. Guo, D. L. Swaney, T. A. Tummino, R. Hüttenhain, R. M. Kaake, A. L. Richards, B. Tutuncuoglu, H. Foussard, J. Batra, K. Haas, M. Modak, M. Kim, P. Haas, B. J. Polacco, H. Braberg, J. M. Fabius, M. Eckhardt, M. Soucheray, M. J. Bennett, M. Cakir, M. J. McGregor, Q. Li, B. Meyer, F. Roesch, T. Vallet, A. Mac Kain, L. Miorin, E. Moreno, Z. Z. C. Naing, Y. Zhou, S. Peng, Y. Shi, Z. Zhang, W. Shen, I. T. Kirby, J. E. Melnyk, J. S. Chorba, K. Lou, S. A. Dai, I. BarrioHernandez, D. Memon, C. Hernandez-Armenta, J. Lyu, C. J. P. Mathy, T. Perica, K. B. Pilla, S. J. Ganesan, D. J. Saltzberg, R. Rakesh, X. Liu, S. B. Rosenthal, L. Calviello, S. Venkataramanan, J. Liboy-Lugo, Y. Lin, X.-P. Huang, Y. Liu, S. A. Wankowicz, M. Bohn, M. Safari, F. S. Ugur, C. Koh, N. S. Savar, Q. D. Tran, D. Shengjuler, S. J. Fletcher, M. C. O'Neal, Y. Cai, J. C. J. Chang, D. J. Broadhurst, S. Klippsten, P. P. Sharp, N. A. Wenzell, D. Kuzuoglu-Ozturk, H.-Y. Wang, R. Trenker, J. M. Young, D. A. Cavero, J. Hiatt, T. L. Roth, U. Rathore, A. Subramanian, J. Noack, M. Hubert, R. M. Stroud, A. D. Frankel, O. S. Rosenberg, K. A. Verba, D. A. Agard, M. Ott, M. Emerman, N. Jura, M. von Zastrow, E. Verdin, A. Ashworth, 0. 
Schwartz, C. d'Enfert, S. Mukherjee, M. Jacobson, H. S. Malik, D. G. Fujimori, T. Ideker, C. S. Craik, S. N. Floor, J. S. Fraser, J. D. Gross, A. Sali, B. L. Roth, D. Ruggero, J. Taunton, T. Kortemme, P. Beltrao, M. Vignuzzi, A. García-Sastre, K. M. Shokat, B. K. Shoichet, N. J. Krogan, A SARS-CoV-2 protein interaction map reveals targets for drug repurposing. Nature 583, 459-468 (2020). doi:10.1038/s41586-020-2286-9 Medline

2. C. Liu, Q. Zhou, Y. Li, L. V. Garner, S. P. Watkins, L. J. Carter, J. Smoot, A. C. Gregg, A. D. Daniels, S. Jervey, D. Albaiu, Research and development on therapeutic agents and vaccines for COVID-19 and related human coronavirus diseases. ACS Cent. Sci. 6, 315-331 (2020). doi:10.1021/acscentsci.0c00272 Medline

3. W.-H. Chen, U. Strych, P. J. Hotez, M. E. Bottazzi, The SARS-CoV-2 vaccine pipeline: An overview. Curr. Trop. Med. Rep. 7, 1-4 (2020). doi:10.1007/s40475-02000201-6 Medline

4. K. K. Chan, D. Dorosky, P. Sharma, S. A. Abbasi, J. M. Dye, D. M. Kranz, A. S. Herbert, E. Procko, Engineering human ACE2 to optimize binding to the spike protein of SARS coronavirus 2. Science 369, 1261-1265 (2020). doi:10.1126/science abc0870 Medline

5. J. D. Walter, C. A. J. Hutter, I. Zimmermann, J. Earp, P. Egloff, M. Sorgenfrei, L. M. Hürlimann, I. Gonda, G. Meier, S. Remm, S. Thavarasah, P. Plattet, M. A. Seeger, Sybodies targeting the SARS-CoV-2 receptor-binding domain. bioRxiv 045419 [Preprint]. 16 May 2020. https://doi.org/10.1101/2020.04.16.045419.

6. L. Cao, I. Goreshnik, B. Coventry, J. B. Case, L. Miller, L. Kozodoy, R. E. Chen, L. Carter, A. C. Walls, Y.-J. Park, E.-M. Strauch, L. Stewart, M. S. Diamond, D. Veesler, D. Baker, De novo design of picomolar SARS-CoV-2 miniprotein inhibitors. Science 370, 426-431 (2020). doi:10.1126/science abd9909 Medline

7. L. Zhang, D. Lin, X. Sun, U. Curth, C. Drosten, L. Sauerhering, S. Becker, K. Rox, R. Hilgenfeld, Crystal structure of SARS-CoV-2 main protease provides a basis for design of improved $\alpha$-ketoamide inhibitors. Science 368, 409-412 (2020). doi:10.1126/science. abb3405 Medline

8. E. C. Smith, M. R. Denison, Coronaviruses as DNA wannabes: A new model for the regulation of RNA virus replication fidelity. PLOS Pathog. 9, e1003760 (2013) doi:10.1371/journal.ppat.1003760 Medline

9. S. Duffy, Why are RNA virus mutation rates so damn high? PLOS Biol. 16, e3000003 (2018). doi:10.1371/journal.pbio.3000003 Medline

10. Z. Zhao, H. Li, X. Wu, Y. Zhong, K. Zhang, Y.-P. Zhang, E. Boerwinkle, Y.-X. Fu, Moderate mutation rate in the SARS coronavirus genome and its implications. BMC Evol. Biol. 4, 21 (2004). doi:10.1186/1471-2148-4-21 Medline

11. M. B. Doud, S. E. Hensley, J. D. Bloom, Complete mapping of viral escape from neutralizing antibodies. PLOS Pathog. 13, e1006271(2017). doi:10.1371/journal.ppat.1006271 Medline

12. T. Phan, Genetic diversity and evolution of SARS-CoV-2. Infect. Genet. Evol. 81, 104260 (2020). doi:10.1016/imeegid.2020.104260 Medline

13. J. Hu, C.-L. He, Q.-Z. Gao, G.-J. Zhang, X.-X. Cao, Q.-X. Long, H.-J. Deng, L.-Y. Huang, J. Chen, K. Wang, N. Tang, A.-L. Huang, D614G mutation of SARS-CoV-2 spike protein enhances viral infectivity. bioRxiv 161323 [Preprint]. 6 July 2020. https://doi.org/10.1101/2020.06.20.161323.

14. A. Baum, B. O. Fulton, E. Wloga, R. Copin, K. E. Pascal, V. Russo, S. Giordano, K. Lanza, N. Negron, M. Ni, Y. Wei, G. S. Atwal, A. J. Murphy, N. Stahl, G. D. Yancopoulos, C. A. Kyratsous, Antibody cocktail to SARS-CoV-2 spike protein prevents rapid mutational escape seen with individual antibodies. Science 369, 1014-1018 (2020). doi:10.1126/science.abd0831 Medline

15. T. N. Starr, A. J. Greaney, S. K. Hilton, K. H. D. Crawford, M. J. Navarro, J. E. Bowen, M. A. Tortorici, A. C. Walls, D. Veesler, J. D. Bloom, Deep mutational scanning of SARS-CoV-2 receptor binding domain reveals constraints on folding and ACE2 binding. Cell 182, P1295-P1310.E20 (2020)._doi:10.1016/j.cell.2020.08.012 Medline

16. J. ter Meulen, E. N. van den Brink, L. L. M. Poon, W. E. Marissen, C. S. W. Leung, F. Cox, C. Y. Cheung, A. Q. Bakker, J. A. Bogaards, E. van Deventer, W. Preiser, H. W. Doerr, V. T. Chow, J. de Kruif, J. S. M. Peiris, J. Goudsmit, Human monoclonal antibody combinationagainst SARS coronavirus: Synergy and coverage of escape mutants. PLOS Med. 3, e237 (2006). doن:10.1371/journal.pmed.0030237Medline

17. L. Enjuanes, S. Zuñiga, C. Castano-Rodriguez, J. Gutierrez-Alvarez, J. Canton, I. Sola, "Molecular basis of coronavirus virulence and vaccine development," in Advances in Virus Research, J. Ziebuhr, Ed. (Elsevier, 2016), vol. 96, pp. 245-286.

18. S. Belouzard, V. C. Chu, G. R. Whittaker, Activation of the SARS coronavirus spike protein via sequential proteolytic cleavage at two distinct sites. Proc. Natl. Acad. Sci. U.S.A. 106, 5871-5876 (2009). doi:10.1073/pnas.0809524106 Medline

19. J. Shang, Y. Wan, C. Luo, G. Ye, O. Geng, A. Auerbach, F. Li, Cell entry mechanisms of SARS-CoV-2. Proc. Natl. Acad. Sci. U.S.A. 117, 11727-11734 (2020). doi:10.1073/pnas.2003138117Medline

20. J. K. Millet, G. R. Whittaker, Host cell entry of Middle East respiratory syndrome coronavirus after two-step, furin-mediated activation of the spike protein. Proc. Natl. Acad. Sci. U.S.A. 111, 15214-15219 (2014). doi:10.1073/pnas.1407087111 Medline

21. X. Ou, Y. Liu, X. Lei, P. Li, D. Mi, L. Ren, L. Guo, R. Guo, T. Chen, J. Hu, Z. Xiang, Z. Mu, X. Chen, J. Chen, K. Hu, Q. Jin, J. Wang, Z. Qian, Characterization of spike glycoprotein of SARS-CoV-2 on virus entry and its immune cross-reactivity with SARS-CoV. Nat. Commun. 11, 1620 (2020). doi:10.1038/s41467-020-15562-9 Medline

22. Z. Song, Y. Xu, L. Bao, L. Zhang, P. Yu, Y. Qu, H. Zhu, W. Zhao, Y. Han, C. Qin, From SARS to MERS, thrusting coronaviruses into the spotlight. Viruses 11, 59 (2019). doi:10.3390/v11010059 Medline

23. R. Yan, Y. Zhang, Y. Li, L. Xia, Y. Guo, Q. Zhou, Structural basis for the recognition of SARS-CoV-2 by full-length human ACE2. Science 367, 1444-1448 (2020). doi:10.1126/science abb2762 Medline

24. Q. Wang, Y. Zhang, L. Wu, S. Niu, C. Song, Z. Zhang, G. Lu, C. Qiao, Y. Hu, K.-Y. Yuen, Q. Wang, H. Zhou, J. Yan, J. Qi, Structural and functional basis of SARS-CoV2 entry by using human ACE2. Cell 181, 894-904.e9 (2020). doi:10.1016/j.cell.2020.03.045 Medline

25. J. Lan, J. Ge, J. Yu, S. Shan, H. Zhou, S. Fan, O. Zhang, X. Shi, O. Wang, L. Zhang, X Wang, Structure of the SARS-CoV-2 spike receptor-binding domain bound to the ACE2 receptor. Nature 581, 215-220 (2020). doi:10.1038/s41586-020-2180-5 Medline

26. D.-A. Silva, S. Yu, U. Y. Ulge, J. B. Spangler, K. M. Jude, C. Labão-Almeida, L. R. Ali, A. Quijano-Rubio, M. Ruterbusch, I. Leung, T. Biary, S. J. Crowley, E. Marcos, C. D. Walkey, B. D. Weitzner, F. Pardo-Avila, J. Castellanos, L. Carter, L. Stewart, S. R. Riddell, M. Pepper, G. J. L. Bernardes, M. Dougan, K. C. Garcia, D. Baker, De novo design of potent and selective mimics of IL-2 and IL-15. Nature 565, 186-191 (2019). doi:10.1038/s41586-018-0830-7 Medline

27. F. Sesterhenn, C. Yang, J. Bonet, J. T. Cramer, X. Wen, Y. Wang, C.-I. Chiang, L. A. Abriata, I. Kucharska, G. Castoro, S. S. Vollers, M. Galloux, E. Dheilly, S. Rosset, P. Corthésy, S. Georgeon, M. Villard, C.-A. Richard, D. Descamps, T. Delgado, E. Oricchio, M.-A. Rameix-Welti, V. Más, S. Ervin, J.-F. Eléouët, S. Riffault, J. T. Bates, J.-P. Julien, Y. Li, T. Jardetzky, T. Krey, B. E. Correia, De novo protein design enables the precise induction of RSV-neutralizing antibodies. Science 368, eaay5051 (2020). do: 10.1126/science aay5051 Medline

28. J. Zhou, A. E. Panaitiu, G. Grigoryan, A general-purpose protein design framework based on mining sequence-structure relationships in known protein structures. Proc. Natl. Acad. Sci. U.S.A. 117, 1059-1068 (2020). doi:10.1073/pnas.1908723117 Medline

29. D.-A. Silva, B. E. Correia, E. Procko, "Motif-driven design of protein-protein interfaces," in Computational Design of Ligand Binding Proteins, B. L. Stoddard, Ed. (Humana, 2016), vol. 1414, pp. 285-304.

30. A. Quijano-Rubio, U. Y. Ulge, C. D. Walkey, D.-A. Silva, The advent of de novo proteins for cancer immunotherapy. Curr. Opin. Chem. Biol. 56, 119-128 (2020). doi:10.1016/i.cbpa.2020.02.002 Medline

31. A. Leaver-Fay, M. Tyka, S. M. Lewis, O. F. Lange, J. Thompson, R. Jacak, K. Kaufman, P. D. Renfrew, C. A. Smith, W. Sheffler, I. W. Davis, S. Cooper, A. Treuille, D. J. Mandell, F. Richter, Y.-E. A. Ban, S. J. Fleishman, J. E. Corn, D. E. Kim, S. Lyskov, M. Berrondo, S. Mentzer, Z. Popović, J. J. Havranek, J. Karanicolas, R. Das, J. Meiler, T. Kortemme, J. J. Gray, B. Kuhlman, D. Baker, P. Bradley, ROSETTA3: An object-oriented software suite for the simulation and design of macromolecules. Methods Enzymol. 487, 545-574 (2011). doi:10.1016/B978-012-381270-4.00019-6 Medline

32. E. Marcos, D.-A. Silva, Essentials of de novo protein design: Methods and applications. WIREs Comput Mol Sci 8, el374 (2018). doi:10.1002/wcms.1374

33. A. Chevalier, D.-A. Silva, G. J. Rocklin, D. R. Hicks, R. Vergara, P. Murapa, S. M. Bernard, L. Zhang, K.-H. Lam, G. Yao, C. D. Bahl, S.-I. Miyashita, I. Goreshnik, J. T. Fuller, M. T. Koday, C. M. Jenkins, T. Colvin, L. Carter, A. Bohn, C. M. Bryan, D. A. Fernández-Velasco, L. Stewart, M. Dong, X. Huang, R. Jin, I. A. Wilson, D. H. Fuller, 
D. Baker, Massively parallel de novo protein design for targeted therapeutics. Nature 550, 74-79 (2017). doi:10.1038/nature23912 Medline

34. T. A. Whitehead, A. Chevalier, Y. Song, C. Dreyfus, S. J. Fleishman, C. De Mattos, C. A. Myers, H. Kamisetty, P. Blair, I. A. Wilson, D. Baker, Optimization of affinity, specificity and function of designed influenza inhibitors using deep sequencing. Nat. Biotechnol. 30, 543-548 (2012). doi:10.1038/nbt.2214 Medline

35. M. Hoffmann, H. Kleine-Weber, S. Schroeder, N. Krüger, T. Herrler, S. Erichsen, T. S. Schiergens, G. Herrler, N.-H. Wu, A. Nitsche, M. A. Müller, C. Drosten, S. Pöhlmann, SARS-CoV-2 cell entry depends on ACE2 and TMPRSS2 and is blocked by a clinically proven protease inhibitor. Cell 181, 271-280.e8 (2020). doi:10.1016/j.cell.2020.02.052 Medline

36. W. Sungnak, N. Huang, C. Bécavin, M. Berg, R. Queen, M. Litvinukova, C. TalaveraLópez, H. Maatz, D. Reichart, F. Sampaziotis, K. B. Worlock, M. Yoshida, J. L. Barnes; HCA Lung Biological Network, SARS-CoV-2 entry factors are highly expressed in nasal epithelial cells together with innate immune genes. Nat. Med. 26, 681-687 (2020). doi:10.1038/s41591-020-0868-6 Medline

37. M. P. Baker, H. M. Reynolds, B. Lumicisi, C. J. Bryson, Immunogenicity of protein therapeutics: The key causes, consequences and challenges. Self Nonself 1, 314322 (2010). doi:10.4161/self.1.4.13904 Medline

38. N. Casadevall, J. Nataf, B. Viron, A. Kolta, J.-J. Kiladjian, P. Martin-Dupont, P. Michaud, T. Papo, V. Ugo, I. Teyssandier, B. Varet, P. Mayeux, Pure red-cell aplasia and antierythropoietin antibodies in patients treated with recombinant erythropoietin. N. Engl. J. Med. 346, 469-475 (2002). doi:10.1056/NEJMoa011931 Medline

39. M. G. Tovey, C. Lallemand, Immunogenicity and other problems associated with the use of biopharmaceuticals. Ther. Adv. Drug Saf. 2, 113-128 (2011). doi:10.1177/2042098611406318 Medline

40. J. Li, C. Yang, Y. Xia, A. Bertino, J. Glaspy, M. Roberts, D. J. Kuter, Thrombocytopenia caused by the development of antibodies to thrombopoietin. Blood 98, 3241-3248 (2001). doi:10.1182/blood.V98.12.3241 Medline

41. M. P. Ettinger, T. W. Littlejohn, S. L. Schwartz, S. R. Weiss, H. H. Mcllwain, S. B. Heymsfield, G. A. Bray, W. G. Roberts, E. R. Heyman, N. Stambler, S. Heshka, C. Vicary, H.-P. Guler, Recombinant variant of ciliary neurotrophic factor for weight loss in obese adults: A randomized, dose-ranging study. JAMA 289, 1826-1832 (2003). doi:10.1001/jama.289.14.1826 Medline

42. M. Findeisen, T. L. Allen, D. C. Henstridge, H. Kammoun, A. E. Brandon, L. L. Baggio, K. I. Watt, M. Pal, L. Cron, E. Estevez, C. Yang, G. M. Kowalski, L. O'Reilly, C. Egan, E. Sun, L. M. Thai, G. Krippner, T. E. Adams, R. S. Lee, J. Grötzinger, C. Garbers, S. Risis, M. J. Kraakman, N. A. Mellet, J. Sligar, E. T. Kimber, R. L. Young, M. A. Cowley, C. R. Bruce, P. J. Meikle, P. A. Baldock, P. Gregorevic, T. J. Biden, G. J. Cooney, D. J. Keating, D. J. Drucker, S. Rose-John, M. A. Febbraio, Treatment of type 2 diabetes with the designer cytokine IC7Fc. Nature 574, 63-68 (2019). doi:10.1038/s41586-019-1601-9 Medline

43. G. Gao, C. Lebherz, D. J. Weiner, R. Grant, R. Calcedo, B. McCullough, A. Bagg, Y. Zhang, J. M. Wilson, Erythropoietin gene therapy leads to autoimmune anemia in macaques. Blood 103, 3300-3302 (2004). doi:10.1182/blood-2003-11-3852 Medline

44. H. Schellekens, N. Casadevall, Immunogenicity of recombinant human proteins: Causes and consequences. J. Neurol. 251(Suppl 2), II4-II9 (2004). doi:10.1007/s00415-004-1202-9 Medline

45. I. Mukovozov, T. Sabljic, G. Hortelano, F. A. Ofosu, Factors that contribute to the immmunogenicity of therapeutic recombinant human proteins. Thromb. Haemost. 99, 874-882 (2008). doi:10.1160/TH07-11-0654 Medline

46. M. Sauerborn, V. Brinks, W. Jiskoot, H. Schellekens, Immunological mechanism underlying the immune response to recombinant human protein therapeutics. Trends Pharmacol. Sci. 31, 53-59 (2010). doi:10.1016/i.tips.2009.11.001 Medline

47. W. B. Alsoussi, J. S. Turner, J. B. Case, H. Zhao, A. J. Schmitz, J. Q. Zhou, R. E. Chen, T. Lei, A. A. Rizk, K. M. McIntire, E. S. Winkler, J. M. Fox, N. M. Kafai, L. B. Thackray, A. O. Hassan, F. Amanat, F. Krammer, C. T. Watson, S. H. Kleinstein, D. H. Fremont, M. S. Diamond, A. H. Ellebedy, A potently neutralizing antibody protects mice against SARS-CoV-2 infection. J. Immunol. 205, 915-922 (2020). doi:10.4049/iimmunol.2000583 Medline

48. M. Schoof, B. Faust, R. A. Saunders, S. Sangwan, V. Rezelj, N. Hoppe, M. Boone, C. Bache Billesbølle, M. Zimanyi, I. Deshpande, J. Liang, A. A. Anand, N. Dobzinski, B. S. Zha, B. Barsi-Rhyne, V. Belyy, A. W. Barile-Hill, S. Gupta, C. R. Simoneau, K.
Leon, K. M. White, S. Nock, Y. Liu, N. J. Krogan, C. Y. Ralston, D. L. Swaney, A. García-Sastre, M. Ott, M. Vignuzzi, QCRG Structural Biology Consortium, P. Walter, A. Manglik, An ultra-high affinity synthetic nanobody blocks SARS-CoV-2 infection by locking Spike into an inactive conformation. bioRxiv 238469 [Preprint]. 17 August 2020. https://doi.org/10.117101/2020.08.08.238469.

49. E. Marcos, B. Basanta, T. M. Chidyausiku, Y. Tang, G. Oberdorfer, G. Liu, G. V. T. Swapna, R. Guan, D.-A. Silva, J. Dou, J. H. Pereira, R. Xiao, B. Sankaran, P. H. Zwart, G. T. Montelione, D. Baker, Principles for designing proteins with cavities formed by curved $\beta$ sheets. Science 355, 201-206 (2017). doi:10.1126/science.aah7389 Medline

50. National Center for Biotechnology Information, "VAST: Non-redundant PDB chain set" (2016); https://structure.ncbi.nlm.nih.gov/Structure/VAST/nrpdb.html.

51. S. Minami, K. Sawada, G. Chikenji, MICAN: A protein structure alignment algorithm that can handle Multiple-chains, Inverse alignments, $C(\alpha)$ only models, Alternative alignments, and Non-sequential alignments. BMC Bioinformatics 14, 24 (2013). doi:10.1186/1471-2105-14-24 Medline

52. J. Xu, Y. Zhang, How significant is a protein structure similarity with TM-score $=$ 0.5? Bioinformatics 26, 889-895 (2010). doi:10.1093/bioinformatics/btg066 Medline

53. Y. Zhang, J. Skolnick, Scoring function for automated assessment of protein structure template quality. Proteins 57, 702-710 (2004). doi:10.1002/prot.20264 Medline

54. D. G. Gibson, L. Young, R.-Y. Chuang, J. C. Venter, C. A. Hutchison 3rd, H. O. Smith, Enzymatic assembly of DNA molecules up to several hundred kilobases. Nat. Methods 6, 343-345 (2009). doi:10.1038/nmeth.1318 Medline

55. C. O. Barnes, A. P. West, K. E. Huey-Tubman, M. A. G. Hoffmann, N. G. Sharaf, P. R. Hoffman, N. Koranda, H. B. Gristick, C. Gaebler, F. Muecksch, J. C. Cetrulo Lorenzi, S. Finkin, T. Hagglof, A. Hurley, K. G. Millard, Y. Weisblum, F. Schmidt, T. Hatziioannou, P. D. Bieniasz, M. Caskey, D. F. Robbiani, M. C. Nussenzweig, P. J. Bjorkman, Structures of human antibodies bound to SARS-CoV-2 spike reveal common epitopes and recurrent features of antibodies. Cell 182, P828-P842.E16 (2020). doi:101016/icell.2020.06.025 Medline

56. C.-L. Hsieh, J. A. Goldsmith, J. M. Schaub, A. M. DiVenere, H.-C. Kuo, K Javanmardi, K. C. Le, D. Wrapp, A. G. Lee, Y. Liu, C.-W. Chou, P. O. Byrne, C. K. Hjorth, N. V. Johnson, J. Ludes-Meyers, A. W. Nguyen, J. Park, N. Wang, D. Amengor, J. J. Lavinder, G. C. Ippolito, J. A. Maynard, I. J. Finkelstein, J. S. McLellan, Structure-based design of prefusion-stabilized SARS-CoV-2 spikes. Science 369, 1501-1505 (2020). doi:101126/science.abd0826 Medline

57. D. N. Mastronarde, Automated electron microscope tomography using robust prediction of specimen movements. J. Struct. Biol. 152, 36-51 (2005). doi:10.1016/i.jsb.2005.07.007 Medline

58. A. Punjani, J. L. Rubinstein, D. J. Fleet, M. A. Brubaker, cryoSPARC: Algorithms for rapid unsupervised cryo-EM structure determination. Nat. Methods 14, 290-296 (2017). doi:10.1038/nmeth.4169 Medline

59. T. D. Goddard, C. C. Huang, T. E. Ferrin, Visualizing density maps with UCS F Chimera. J. Struct. Biol. 157, 281-287 (2007). doن:10.1016/j.jsb.2006.06.010 Medline

60. T. C. Terwilliger, P. D. Adams, P. V. Afonine, O. V. Sobolev, A fully automatic method yielding initial models from high-resolution cryo-electron microscopy maps. Nat. Methods 15, 905-908 (2018). doi:10.1038/s41592-018-0173-1 Medline

61. P. Emsley, K. Cowtan, Coot: Model-building tools for molecular graphics. Acta Crystallogr. D Biol. Crystallogr. 60, 2126-2132 (2004) doi:10.1107/S0907444904019158 Medline

62. V. B. Chen, W. B. Arendall 3rd, J. J. Headd, D. A. Keedy, R. M. Immormino, G. J. Kapral, L. W. Murray, J. S. Richardson, D. C. Richardson, MolProbity: All-atom structure validation for macromolecular crystallography. Acta Crystallogr. D Biol. Crystallogr. 66, 12-21 (2010). doi:10.1107/S0907444909042073 Medline

63. E.-M. Strauch, S. M. Bernard, D. La, A. J. Bohn, P. S. Lee, C. E. Anderson, T. Nieusma, C. A. Holstein, N. K. Garcia, K. A. Hooper, R. Ravichandran, J. W. Nelson, W. Sheffler, J. D. Bloom, K. K. Lee, A. B. Ward, P. Yager, D. H. Fuller, I. A. Wilson, D. Baker, Computational design of trimeric influenza-neutralizing proteins targeting the hemagglutinin receptor binding site. Nat. Biotechnol. 35, 667-671 (2017). doi:10.1038/nbt3907Medline

64. L. Benatuil, J. M. Perez, J. Belk, C.-M. Hsieh, An improved yeast transformation 
method for the generation of very large human antibody libraries. Protein Eng. Des. Sel. 23, 155-159 (2010). doi:10.1093/protein/gzq002 Medline

65. M. T. Koday, J. Nelson, A. Chevalier, M. Koday, H. Kalinoski, L. Stewart, L. Carter, T. Nieusma, P. S. Lee, A. B. Ward, I. A. Wilson, A. Dagley, D. F. Smee, D. Baker, D. $\mathrm{H}$. Fuller, A computationally designed hemagglutinin stem-binding protein provides in vivo protection from influenza independent of a host immune response.PLOS Pathog. 12, e1005409 (2016). doi:10.1371/journal.ppat.1005409 Medline

66. D. K. W. Chu, Y. Pan, S. M. S. Cheng, K. P. Y. Hui, P. Krishnan, Y. Liu, D. Y. M. Ng, C. K. C. Wan, P. Yang, Q. Wang, M. Peiris, L. L. M. Poon, Molecular diagnosis of a novel coronavirus (2019-nCoV) causing an outbreak of pneumonia. Clin. Chem. 66 , 549-555 (2020). doi:10.1093/clinchem/hvaa029 Medline

67. P. Virtanen, R. Gommers, T. E. Oliphant, M. Haberland, T. Reddy, D. Cournapeau, E. Burovski, P. Peterson, W. Weckesser, J. Bright, S. J. van der Walt, M. Brett, J. Wilson, K. J. Millman, N. Mayorov, A. R. J. Nelson, E. Jones, R. Kern, E. Larson, C. J. Carey, I. Polat, Y. Feng, E. W. Moore, J. VanderPlas, D. Laxalde, J. Perktold, R. Cimrman, I. Henriksen, E. A. Quintero, C. R. Harris, A. M. Archibald, A. H. Ribeiro, F. Pedregosa, P. van Mulbregt; SciPy 1.0 Contributors, SciPy 1.0: Fundamental algorithms for scientific computing in Python. Nat. Methods 17, 261-272 (2020). doi:10.1038/s41592-019-0686-2 Medline

\section{ACKNOWLEDGMENTS}

The authors thank Michael Dougan, Leslie Aberman, Umut Ulge, Julie Rathbun, and Jonathan Drachman for useful discussions and comments on this manuscript; Neoleukin Therapeutics, Inc. ("Neoleukin") for supporting this work. All the computational resources for the de novo protein design were provided by Neoleukin's high-performance "Neo" computational cluster. We thank Drs. Songye Chen and Andrey Malyutin (Caltech) for maintaining electron microscopes, and Dr. Jost Vielmetter and the Protein Expression Center in the Beckman Institute at Caltech for expression assistance. Funding: NIH grants Al145296 and Al127463, and Department of Defense grant subcontract to M.G.Jr.; P50 8 P50 Al150464-13 and the Caltech Merkin Institute for Translational Research to P.J.B..; The Hanna Gray Fellowship Program from the Howard Hughes Medical Institute and the Post-doctoral Enrichment Program from the Burroughs Wellcome Fund to C.O.B; HHSN272201400006C from NIAID, NIH to H.-L.Y and R01 Al089728 to R.S.B. Electron microscopy was performed in the Caltech Beckman Institute Resource Center for Transmission Electron Microscopy. This project was also supported by the North Carolina Policy Collaboratory at the University of North Carolina at Chapel Hill with funding from the North Carolina Coronavirus Relief Fund established and appropriated by the North Carolina General Assembly. T.M.R. is supported by the Georgia Research Alliance as an Eminent Scholar. Neoleukin is a trademark of Neoleukin. The views and opinions expressed in this article are those of the authors and do not necessarily reflect the position of Neoleukin. Author contributions: T.W.L. designed and coordinated the research, developed computational design methods, designed de novo protein decoys of ACE2, characterized designs, and wrote the manuscript; R.V. designed de novo proteins, performed molecular biology, characterized and optimized the designs, and wrote the manuscript; N.C. designed de novo proteins, characterized and optimized the designs, and wrote the manuscript; J.W.N. designed de novo proteins, characterized and optimized the designs, performed molecular biology, performed SSM experiments, and wrote the manuscript; M.J.W. designed de novo proteins, performed molecular biology, characterized and optimized the designs, and wrote the manuscript; W.S. performed neutralization assays with the live SARS-CoV-2 virus in Vero E6 cells and edited the manuscript; C.O.B. performed cryo-EM data collection and structure solutions and analyzed the structure together with P.J.B.; T.-Y.H. performed cell-neutralization assays with the live SARS-CoV-2 NanoLuc virus in Calu-3 cells; K.E.-N. performed cellneutralization assays with the live SARS-CoV-2 NanoLuc virus in Calu- 3 cells; Y.J.H. developed the nLUC reporter virus; K.Y. designed and performed ACE2 competition assays and developed methods to quantify the de novo designs in tissue lysates; T.P. designed de novo proteins and purified and characterized the de novo proteins; M.M. designed de novo proteins; A.P. designed de novo proteins and performed binding characterizations; U.Y.L. designed de novo proteins; M.L.M. performed pharmacokinetic studies in mice, coordinated the research for cross reactivity binding assay and edited the manuscript; J.C. performed pharmacokinetic studies in mice; Z.B.R. and T.M.R. performed the SARS-CoV-2 viral protection studies in hamsters; A.C. performed ACE2 enzymatic assay and cytotoxicity assays with VeroE6; T.B. purified and characterized the de novo proteins; H.P. performed mass spectrometry; N.S.C. performed molecular biology; J.Ca. developed and implemented computational tools for collaborative de novo protein design; Y.-R.L. designed de novo proteins; A.J.-D. coordinated project operations and wrote the manuscript; R.S.B. coordinated the development of the nLUC reporter virus and edited the paper; C.D.W. coordinated the research for ACE2 competition assays and methods to quantify the de novo designs and edited the paper; R.S. coordinated the research for in vitro neutralization testing, in vivo viral challenge modeling and in vivo pharmacokinetics of the de novo proteins and edited the paper; D.H.F. designed the in vivo experiments; M.G.Jr. coordinated and directed the research for in vitro NanoLuc SARS-CoV-2 neutralization and edited the paper; L.M.B.-M. designed de novo proteins, coordinated the purification and characterization of the de novo proteins and edited the paper; H.-L.Y. coordinated the research for in vitro SARS-CoV-2 neutralization and edited the paper; D.-A.S. generated the original idea to design the de novo decoys to neutralize SARS-CoV-2, designed the research, developed computational design selection strategies, wrote the manuscript, and directed the effort. Competing interests: T.W.L., N.C., J.W.N., and D.-A.S are inventors on provisional patent applications for the de novo decoys described in this work. D.-A.S. and C.D.W. are co-founders of Neoleukin Therapeutics. Neoleukin authors own options and/or stock in the company. Data and materials availability:PyRosetta code used to generate initial perturbations for mobile secondary structure elements is available in the supplemental materials, appendix A. The cryo-EM maps generated from cryo-EM studies of the CTC-445.2-S 6P complex (states 1-4) have been deposited at the Electron Microscopy Databank (EMDB,786 http://wwwemdataresource.org/) under the following accession codes: EMD-22913 (state 1), EMD-22914 (state 2), EMD22915 (state 3), and EMD-22916 (state 4). The atomic coordinates for the CTC445.2-S 6P complex (state 4) have been deposited at the PDB (http://www.rcsb.org/) under the accession code 7KL9. Neoleukin materials may be made available to academic noncommercial researchers through a material transfer agreement upon request. This work is licensed under a Creative Commons Attribution 4.0 International (CC BY 4.0) license, which permits unrestricted use, distribution, and reproduction in any medium, provided the original work is properly cited. To view a copy of this license, visit https:/creativecommons.org/licenses/by/4.0/. This license does not apply to figures/photos/artwork or other content included in the article that is credited to a third party; obtain authorization from the rights holder before using such material.

\section{SUPPLEMENTARY MATERIALS}

science sciencemag.org/cgi/content/full/science abe0075/DC1

Materials and Methods

Figs. S1 to S21

Tables S1 to S5

Appendix A: Python/PyRosetta code

References (49-67)

MDAR Reproducibility Checklist

31 July 2020; accepted 29 October 2020

Published online 5 November 2020

10.1126/science.abe0075 

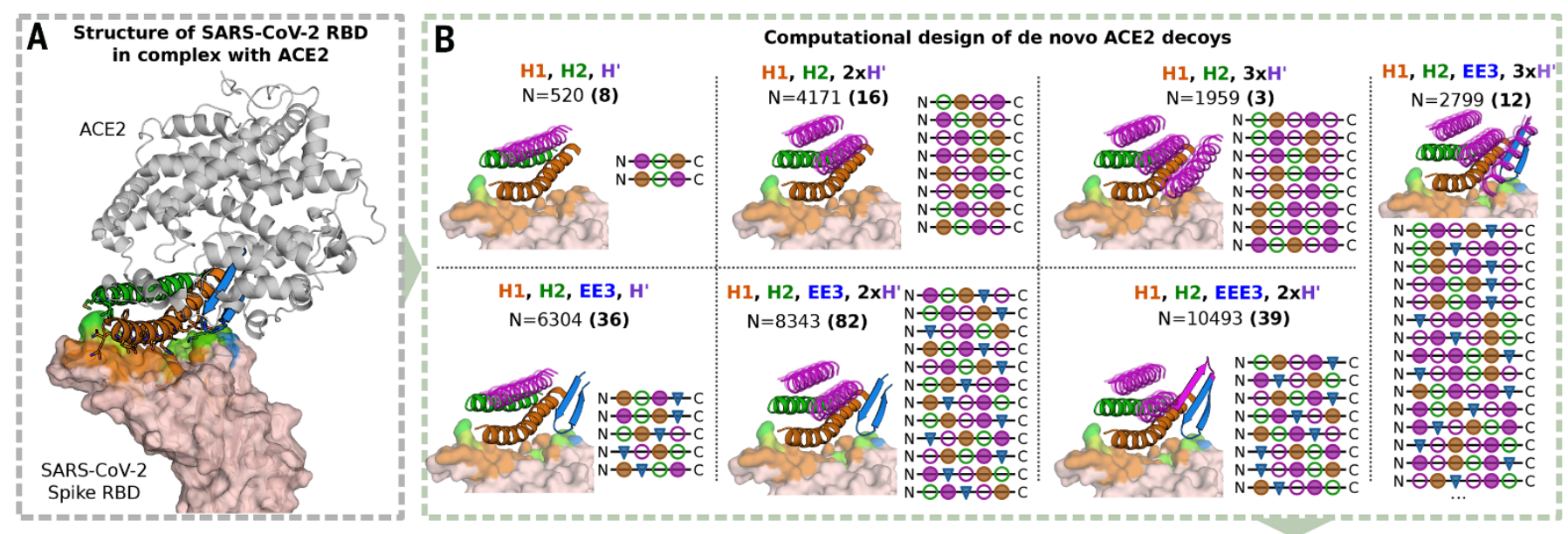
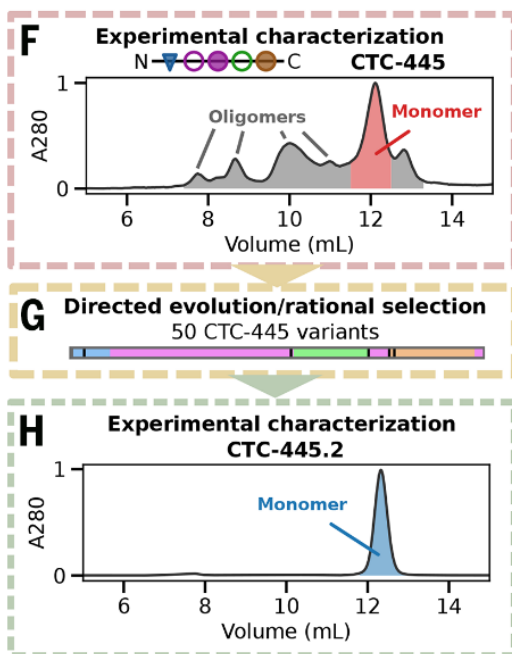

J

March 4 (A)

Day -2

Structure released

(PDB 6vw1)

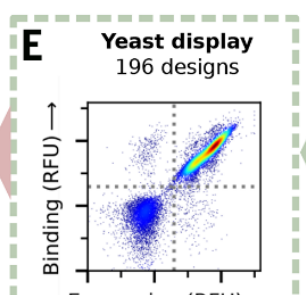

Expression (RFU) $\rightarrow$

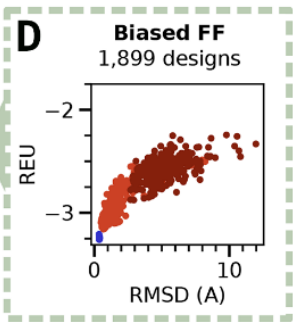

| Inhibition of SARS-CoV-2 RBD binding to ACE2

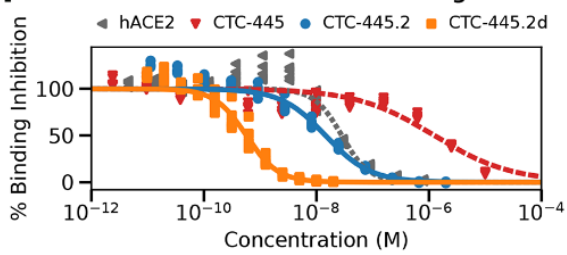

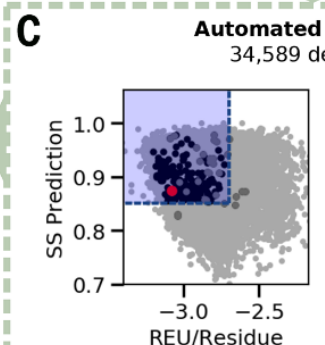

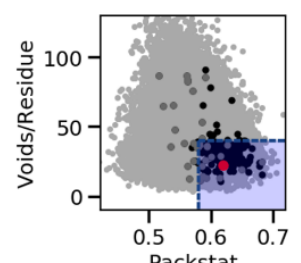

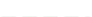
filtering
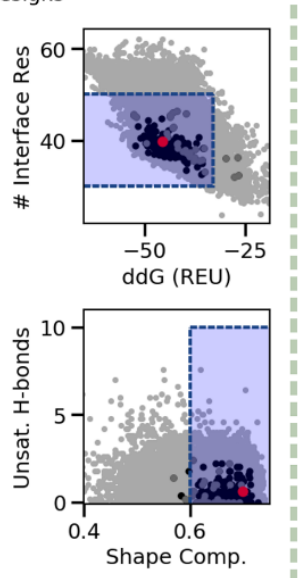

Day 69 (I)

Inhibition of SARS-CoV-2 RBD binding to

Day 27 (F) Binding of purified CTC-445 to SARS-CoV-2 RBD
Day 49 (G)

Optimizing mutations identified and combined

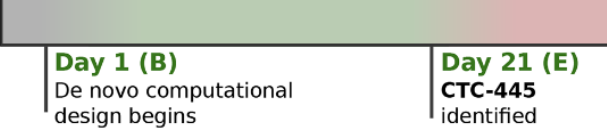

Day $67(\mathrm{H})$
Inhibition of SARS-CoV-2 RBD binding to ACE2 by (monovalent) CTC-445.2 
Fig. 1. Design and characterization of de novo ACE2 decoys. (A) ACE2 (gray) and its binding motifs (H1 19-52, orange; H2 55-84, green; EE3 346-360, blue) in complex with SARS-CoV-2 RBD (pink). Three starting structures were simultaneously used as targets (see main text); 6VW1 is shown. (B) De novo secondary structure elements (magenta) were computationally generated to stabilize $\mathrm{H} 1, \mathrm{H} 2$, and EE3. Seven combinations of secondary structure elements were considered. Circles indicate $\alpha$-helices, triangles indicate $\beta$-sheets; filled circles are helices oriented forward and empty circles are the opposite. We used Rosetta to generate fully connected backbones ("protein_mimic_designer" algorithm) and amino acid sequences predicted to fold into the target structure. In all cases, the binding interface of ACE2 with the SARS-CoV-2 RBD was preserved intact (see the materials and methods). (C) Automatic computational filtering based on 8 metrics selected the best candidates. The RMSD of the binding motifs to ACE2 was also used as a quality check. The dots indicate the mean computational score for each design scored against the three target RBD structures. Designs selected for experimental testing are shown in black. Our best design, CTC-445, is shown in red. The blue boxes indicate the filtering thresholds (see the materials and methods). (D) Designs that passed filtering were subjected to biased forward folding simulations (see the materials and methods), here shown for CTC-445, including the unsalted biased simulation (brown), the native-salted (orange), and relaxation (blue). (E) The top 196 designs were selected for yeast display screening using a combination of Rosetta score per residue, ddG, and the folding simulations (see the materials and methods); The designs were individually assessed for specific binding to SARS-CoV-2 spike RBD (Fc fusion, $200 \mathrm{nM}$ ). The plot for CTC-445 is shown. (F) CTC-445 was recombinantly expressed and purified by affinity chromatography (see the materials and methods). Analytical size exclusion chromatography (SEC) for CTC-445 revealed the presence of oligomeric species; (G) CTC-445 was optimized by directed evolution and rational combination of the observed favorable mutations, leading to $(\mathrm{H})$ CTC-445.2 (SEC) which is mainly monomeric in solution and $1000 x$ more potent to compete ACE2 than its parent (see "G"); we further optimized the potency of our molecule by generating a bivalent version named CTC-445.2d; (I) Potency of designs to outcompete binding of SARS-CoV-2 to ACE2, as measured by competition ELISA assays using a constant concentration of 0.4 nM ACE2. (J) Timeline of the de novo protein design and optimization pipeline. Timewise, a green color indicates phases that we believe were carried out optimally, red can potentially be avoided in future efforts, and yellow are phases that can potentially be expedited by using more advanced/automated methods for gene synthesis, cloning and high-throughput screening. 

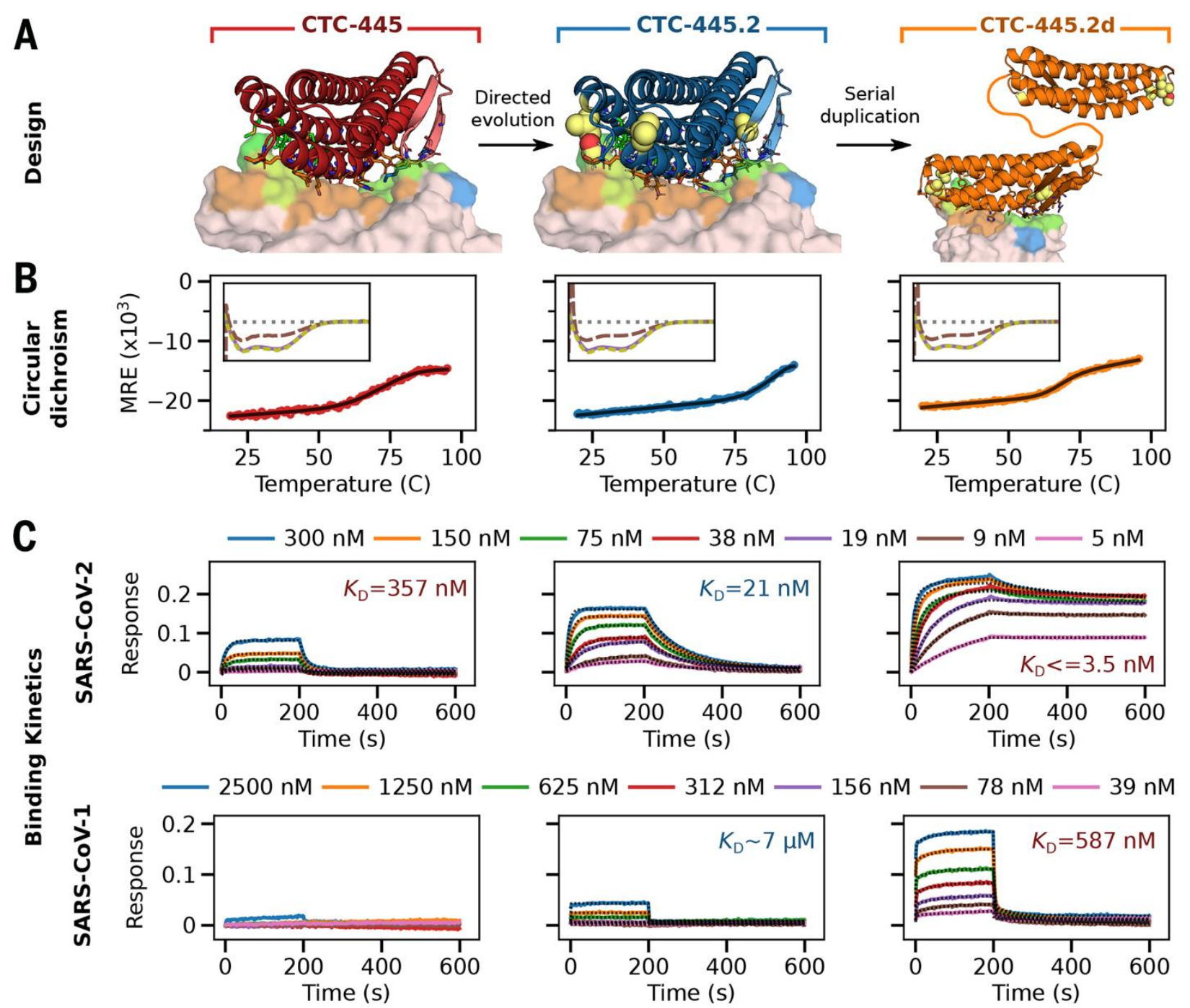

$156 \mathrm{nM}-78 \mathrm{nM}-39 \mathrm{nM}$

Fig. 2. Stability and binding of the de novo protein decoys CTC-445, CTC-445.2 and CTC-445.2d. (A) Design models of CTC-445, CTC-445.2 and CTC-445.2d. CTC-445.2 contains 5 mutations that were guided by directed evolution experiments. CTC-445.2d is a bivalent variant composed of two CTC-445.2 subunits linked by a 16-mer flexible GS linker (sequence -GGGSGGSGSGGSGGGS-); (B) Circular dichroism of recombinantly expressed CTC445 (red), CTC-445.2 (blue) and CTC-445.2d (orange). Thermally-induced meltings of the decoys were followed by its circular dichroism signal at $208 \mathrm{~nm}$ (heating rate $2^{\circ} \mathrm{C} / \mathrm{min}$ ). The inset shows far UV wavelength spectra at $20^{\circ} \mathrm{C}$ (purple), after heating to $\sim 95^{\circ} \mathrm{C}$ (brown) and after cooling the heated sample to $20^{\circ} \mathrm{C}$ (green dashed). Complete ellipticity-spectra recovery (full reversibility) upon cooling was observed in all cases. Calculated $T_{m}$ values for CTC445, CTC-445.2 and CTC-445.2d are 75.3 $\pm 0.2^{\circ} \mathrm{C}, \approx 93^{\circ} \mathrm{C}$ and 71.7. $\pm 0.2^{\circ} \mathrm{C} ; \mathrm{C}$ ) Binding was assessed using biolayer interferometry (OCTET) binding assays of CTC-445, CTC-445.2 and CTC-445.2d against immobilized SARS-CoV-2 RBD (top) or SARS-CoV-1 RBD (bottom) (see table S1). The model fitting is shown with dotted black lines. 

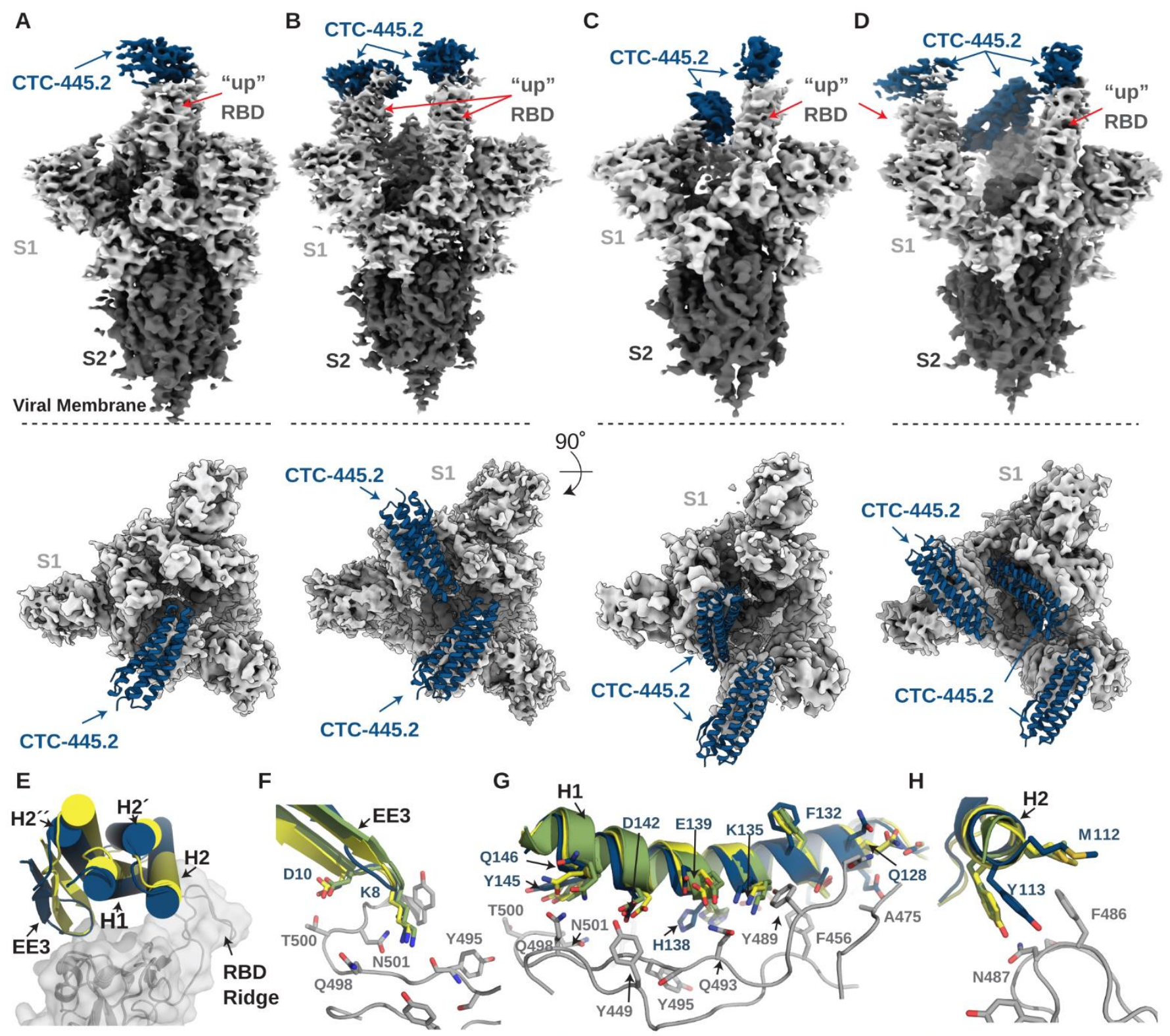

Receptor Binding Domain (RBD)

ACE2 CTC-445.2 cryo-EM

CTC445.2 computational
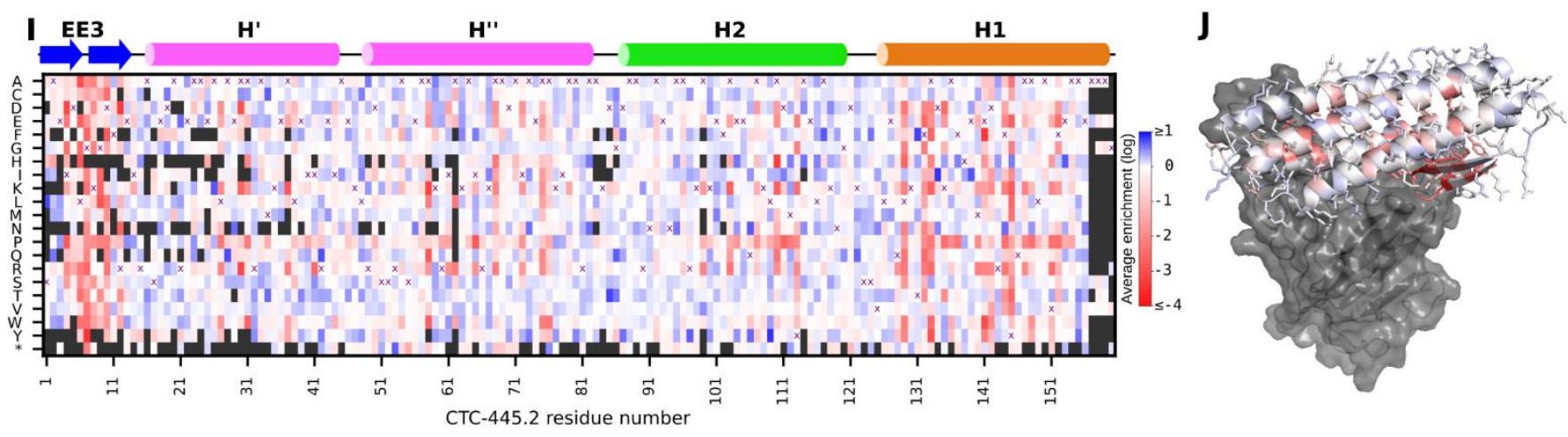
Fig. 3. CryoEM structure of CTC-445.2-S complex. (A to D) cryoEM reconstructions of CTC445.2 (blue) bound to soluble spike trimers (gray). 3D classification revealed 4 distinct classes: one CTC445.2 bound to an "up" RBD (A), two CTC445.2 bound to two "up" RBDs (B), two CTC-445.2 bound to one "up" and one "down" RBD (C), and three CTC-445.2 bound to two "up" and one "down" RBD (D). (E) Overlay of computationally modeled (yellow) and experimentally determined via cryoEM (blue) CTC445.2-RBD; the C $\boldsymbol{\alpha}$ RMSD between the design model and the refined experimental structure is $1.1 \AA$. ( $\mathrm{F}$ to $\mathrm{H}$ ) Comparison of cryoEM CTC-445.2 (blue), computationally modeled CTC445.2 (yellow), and hACE2 (green) at the interface of the RBD (gray). (I) Deep mutational scanning heat map showing the average effect on the enrichment for single site mutants of CTC-445.2 when assayed by yeast display for binding to the SARS-CoV-2 RBD (binding assayed at RBD concentrations of 100 pM, 50 pM, 25 pM, 12.5 pM, 6.25 pM, 3.125 pM, and 1.5625 pM, see the materials and methods); (J) Design model of CTC-445.2 colored by average enrichment at each residue position (from the data in "I") bound to SARS-CoV-2 RBD (gray). As expected, mutations in the core of the design are generally disallowed as well as in the positions involved in binding to the RBD. The deep mutational scanning revealed that there is still ample room to further improve the binding affinity of CTC-445.2, including mutations in the binding interface that in principle could afford higher potency and selectivity at the cost of compromising the decoy's mutational escape resiliency (see Fig. 4). 
A
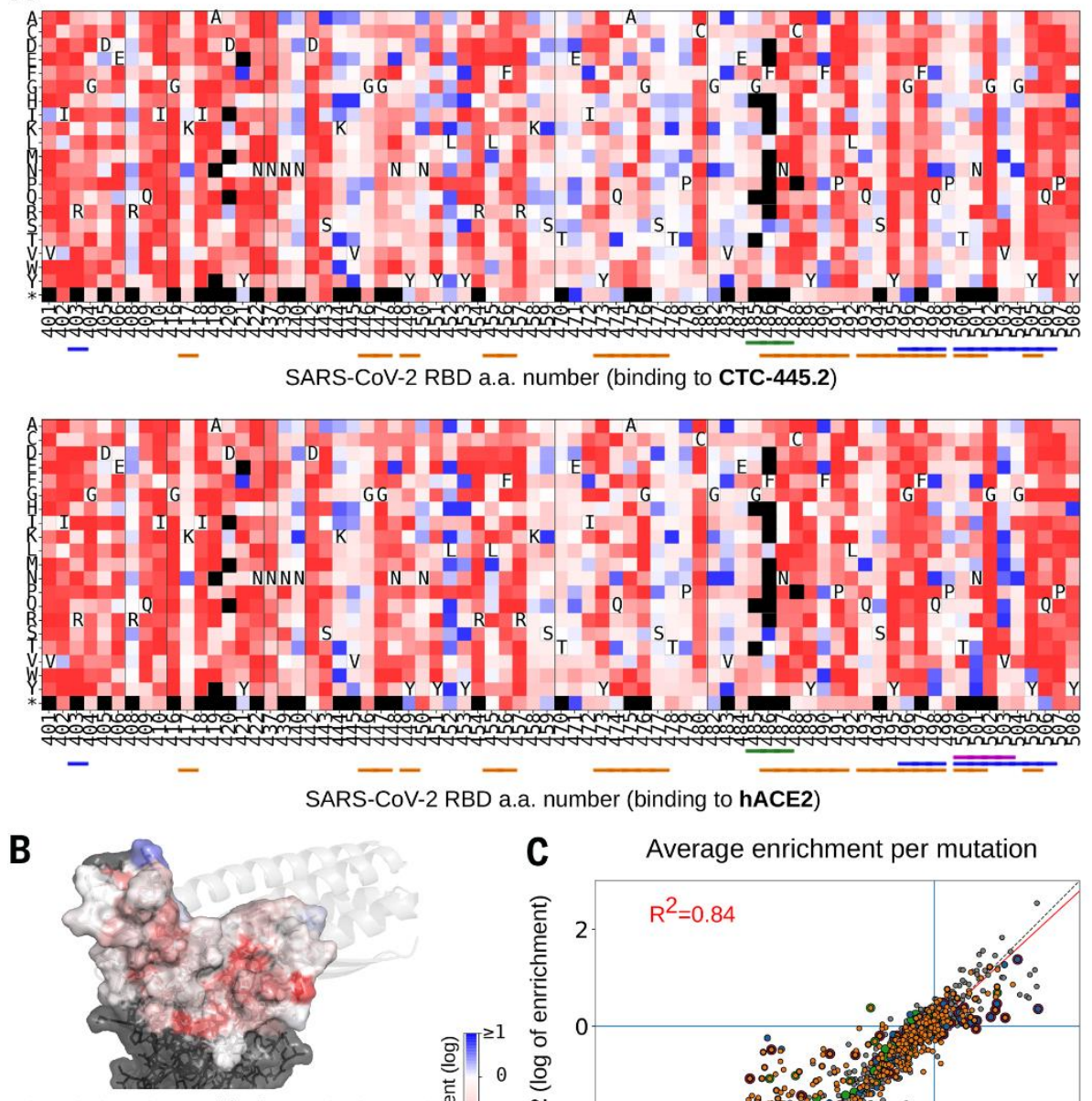

SARS-CoV-2 RBD binding to CTC-445.2
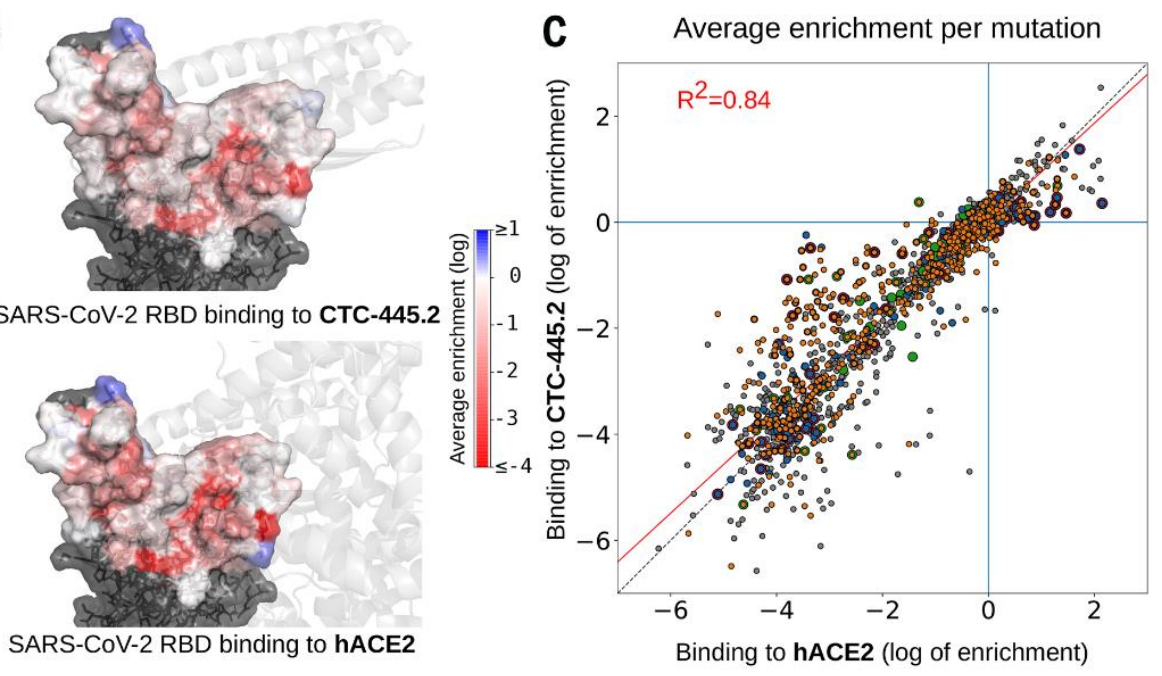

Fig. 4. Resilience of CTC-445.2 to SARS-CoV-2 RBD mutational escape. (A) Deep mutational scanning (DMS) of the SARS-CoV-2 RBD interface was performed to assess the effect on binding (by yeast display) to CTC-445.2 (top) or hACE2 (bottom) at 8 different concentrations ( $656 \mathrm{nM}, 218 \mathrm{nM}, 72 \mathrm{nM}, 24 \mathrm{nM}, 8 \mathrm{nM}, 2 \mathrm{nM}, 0.3 \mathrm{nM}$ and $0.1 \mathrm{nM}$; fig. S16 and materials and methods). The heatmaps indicate the effect on binding for each possible single amino acid mutation in the RBD binding interface for hACE2 (see the materials and methods). The results are the average over all the concentrations tested. A black square represents lack of expression in the naive (unselected) library. The color bars at the bottom indicate which secondary structure element a given RBD residue interacts with ( $\mathrm{H} 1$ : orange, $\mathrm{H} 2$ : green, EE3: blue and H4: magenta), 1700 single-mutations were targeted by the experiment; (B) the SARS-CoV-2 RBD surface is colored according to the per-residue averaged enrichments for binding to the (top) CTC-445.2 or (bottom) hACE2. For reference, the structure of CTC-445 or ACE-2 (respectively) is shown in semi-transparent gray cartoons; (C) The 2-D scatter plots compare the enrichment values (as in "A)") for the DMS of the RBD binding to CTC-445.2 (y-axis) vs. hACE2 ( $x$-axis). There is a high correlation between the effect of RBD mutations in the binding of both molecules, demonstrating the mutational resilience of the de novo decoy (Pearson $r=0.92$ ). 

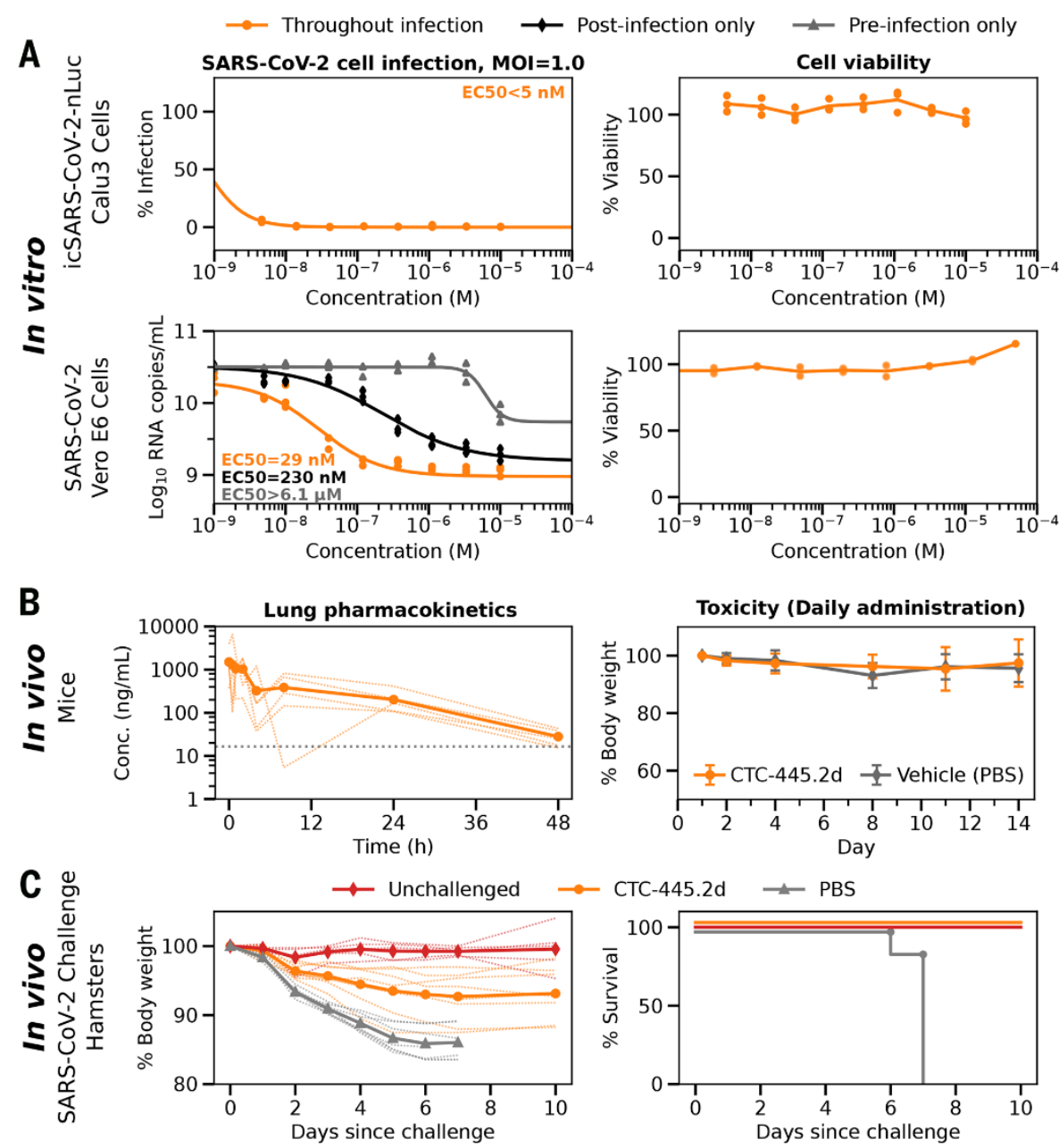

Fig. 5. In vitro virus neutralization by CTC-445.2d. (A) (upper left) In vitro neutralization of NanoLuc SARS-CoV-2 by CTC-445.2d in Calu-3 cells after a 72 hours incubation at MOI 1.0; (upper right) A cell viability assay (48 hours) confirmed that the decoys are not cytotoxic to Calu-3; (lower left) In vitro neutralization of live BetaCoV/Hong Kong/VM20001061/2020 SARS-CoV-2 virus in Vero E6 cells at MOI 1.0). The cells were incubated with CTC-445.2d throughout infection (i.e., before infection, during infection, and post infection) (orange), post-infection only (black) and pre-infection only (gray). SARS-CoV-2 RNA copy numbers were determined by quantitative real-time RT-PCR. All assays were performed in triplicate unless otherwise noted, and all data points are shown. (lower right) Cell viability in Vero E6 cells was independently performed (CCK8 assay) and confirmed that the de novo decoys are not cytotoxic.; (B) In vivo mouse pharmacokinetics and tolerability of intranasally administered CTC-445.2d. (Left) the plot shows the concentration of fully functional CTC-445.2d (i.e., capable of binding to the SARS-CoV-2 RBD; see the materials and methods) found in homogenized lungs of Balb/c mice after a single $100 \mu \mathrm{g}$ dose, measured at various times after dosing ( $n=5$ mice); (right) body weight of mice after repeat daily intranasal doses of CTC-445.2d (100 $\mu$; $\mathrm{n}=18$ at day 0 ) compared to control (PBS-treated) mice $(n=5)$. At each time point, 3 CTC-445.2d-treated mice were sacrificed for lung examination. Weight data shown is for the remaining mice $(\mathrm{n}=18,15,12,9,6$ and 3 at days $1,2,4$, 8,11 , and 14, respectively). No significant weight loss or lung abnormalities were observed. Error bars are the standard deviation; (C) In vivo Syrian hamster SARS-CoV-2 challenge; (left) Body weight measurements through day 10 for unchallenged hamsters ( $n=5$, red) compared to SARS-CoV-2 challenged hamsters treated either with a single dose of CTC-445.2d (day 0 at $-12 \mathrm{H})(n=8$, orange), or PBS day -1 , day 0 at $-12 \mathrm{H}$, day 1 and day 2$)(n=7$, grey); (right) survival plot, hamsters were euthanized when they displayed clinical signs of respiratory distress according to protocol clinical scoring criteria (see the materials and methods). At the end of the experiment, all hamsters treated with the de novo decoy CTC-445.2d survived exhibiting moderate weight loss, while hamsters treated with vehicle didn't survive past day-7 due to severe weight loss and other complications from the viral infection (see table S5). 